\title{
Conocimientos y prácticas de las agentes educativas y condiciones de salud bucal de niños del municipio de Santa Rosa de Cabal, Colombia
}

\author{
Knowledge and practices of educational agents and oral health conditions of children in the municipality of \\ Santa Rosa de Cabal, Colombia
}

\author{
Melissa Katherine Sánchez-Peña1* orcid.org/0000-0003-1590-6270 \\ Johnny Alexander Galvis-Aricapa' orcid.org/0000-0001-6730-4947 \\ Santiago Álzate-Urrea' orcid.org/0000-0003-3929-4205 \\ Dayanna Lema-Agudelo' orcid.org/0000-0002-3966-5048 \\ Laura Michelly Lobón-Córdoba' orcid.org/0000-0001-9000-9436 \\ Yency Quintero-García' orcid.org/0000-0002-2040-3531 \\ Sandra Liliana Carmona-Medina' orcid.org/0000-0001-5985-2687
}

1 Fundación Universitaria Autónoma de las Américas. Pereira, Colombia prácticas de las agentes educativas y condiciones de salud bucal de niños del municipio de Santa Rosa de Cabal, Colombia. Univ. Salud. 2019;21(1):27-37. DOI: http://dx.doi.org/10.22267/rus.192101.137

\section{Resumen}

Introducción: La prevalencia modificada de caries en la primera infancia es de 61,92\%, el desconocimiento en salud bucal por parte de cuidadores es una de las causas reportadas. Objetivo: Determinar conocimientos y prácticas de las agentes educativas y condiciones de salud bucal de niños de los hogares comunitarios y Centros de Desarrollo Infantil del Instituto Colombiano de Bienestar Familiar de Santa Rosa de Cabal 2016. Materiales y métodos: Estudio cuantitativo, descriptivo y transversal. Se aplicó encuestas de caracterización a 198 niños y 20 agentes educativas, de Conocimientos Actitudes y Prácticas e índices odontológicos. Se aplicó estadística univariada y $\mathrm{Chi}^{2} \mathbf{R e s u l t a d o s}^{\mathrm{El}}$ $90 \%$ de las agentes reconocen la caries como la enfermedad más frecuente, $50 \%$ realizan cepillado de los infantes sin utilizar seda dental. Se evidenció prevalencia modificada de caries en $63,6 \%$ y promedio de índice 0'Leary $61,3 \%$. Existe asociación entre el índice ceo-d (cariados, extraídos, obturados), área de residencia y estrato socioeconómico con valor $\mathrm{p}<0,05$. Conclusiones: Las agentes evidencian vacíos conceptuales que requieren abordaje de educación por parte de odontólogos. El estado de salud bucal de la primera infancia indica un porcentaje por encima de la prevalencia modificada de caries a nivel nacional y el índice 0’Leary riesgo de enfermedades bucodentales.

Palabras clave: Niño; salud bucal; cuidadores, caries dental; placa bacteriana. (Fuente: DeCS, Bireme).

\begin{abstract}
Introduction: The modified prevalence of caries in early childhood is $61.92 \%$. Ignorance in oral health on the part of caregivers is one of the reported causes. Objective: To determine knowledge and practices of educational agents and oral health conditions of children in community households and child development centers of the Colombian Family Welfare Institute (ICBF) in Santa Rosa de Cabal in 2016. Materials and methods: A quantitative, descriptive and transversal study was made. Characterization surveys were applied to 198 children and 20 educational agents about knowledgeable attitudes and practices and dental indices. Univariate and $\mathrm{Chi}^{2}$ statistics were applied. Results: $90 \%$ of the agents recognize caries as the most frequent disease, $50 \%$ perform brushing of children without using dental
\end{abstract}


floss. Modified caries prevalence was demonstrated in $63.6 \%$ and $61.3 \%$ average 0 'Leary index. There is an association between the CEO-D Index, area of residence and socioeconomic strata with $p<0.05$ value. Conclusions: Agents demonstrate conceptual gaps that require an education approach by dentists. The state of oral health of early childhood indicates a percentage above the modified prevalence of caries at the national level and the index 0'Leary risk of oral diseases.

Key words: Child; oral health; caregivers; dental caries; dental plaque. (Source: DeCS, Bireme).

\section{Introducción}

La primera infancia ha sido definida como el periodo comprendido desde la gestación hasta los ocho años de edad y es considerada como una etapa importante debido al proceso de crecimiento y desarrollo que se lleva a cabo en dicho lapso. Por este motivo, se debe tener una atención especial en los niños que se encuentran en esta etapa y garantizar su desarrollo adecuado a través de políticas y estrategias que beneficien su calidad de vida; considerando sus condiciones generales de salud y salud bucal, en la formulación de dichas herramientas ${ }^{(1,2)}$. Existen diferentes estudios que dan cuenta del estado de vulnerabilidad de la primera infancia a nivel mundial, con tres grandes amenazas: la pobreza, los conflictos armados y el Síndrome de Inmunodeficiencia Adquirida (SIDA). En Colombia se reporta un número significativo de niños en la primera infancia en situación de pobreza, pobreza extrema y víctimas directas o indirectas del conflicto armado, casos de maltrato, violación de los derechos humanos, entorpeciendo el crecimiento físico y el desarrollo psicológico, social, cultural y económico de esta población(3-6).

Como parte de la solución a esta problemática del país, el Ministerio de Educación Nacional, las universidades colombianas $\mathrm{y}$ el Instituto Colombiano de Bienestar Familiar (ICBF) comenzaron la formación de madres comunitarias, que actualmente son llamadas agentes educativas debido a su cualificación en el trabajo pedagógico y a los procesos de profesionalización que han realizado, para fomentar el adecuado crecimiento y desarrollo de la primera infancia, priorizando cuatro aspectos: la nutrición, la protección, la salud y la educación inicial $(7,8)$. Este programa llevado a cabo en hogares comunitarios y Centros de Desarrollo
Infantil (CDI), ubicados en varios municipios colombianos incide positivamente en los cuatro aspectos fundamentales del desarrollo $\mathrm{y}$ crecimiento de la primera infancia $(7,8)$. Las mujeres que se dedican a la labor de agentes educativas tienen como función contribuir en el cuidado y la protección de niños durante ocho horas diarias, según las características del territorio y los respectivos contextos a los que pertenecen; en este lapso de tiempo realizan actividades de promoción de la salud en general y el cuidado de la salud bucal.

Un estudio realizado en la ciudad de Medellín(9), muestra la percepción de las agentes educativas, con respecto a las necesidades en salud bucal de niños de 2 a 5 años, donde se evidencia la falta de acceso y oportunidad de atención odontológica, los pocos espacios dedicados a la educación para la salud bucal, la falta de capacitación a personas que están a cargo de los menores, como son los padres, madres y agentes educativas, quienes manifiestan limitaciones por la escasa información que tienen en salud bucal.

De acuerdo a lo anterior y teniendo en cuenta la importancia del componente bucal en la primera infancia, es necesario referenciar algunas cifras del Estudio Nacional de Salud Bucal IV (ENSAB IV)(10) donde la experiencia modificada de caries para los niños entre 1, 3 y 5 años en su dentición temporal medida por el índice COP (cariados, obturados, perdidos) según International Caries Detection and Assessment System (ICDAS) es del $66,91 \%$, con un comportamiento para estas edades de $29,31 \%$ en el primer año, $83,03 \%$ a los 3 años y 88,83\% a los 5 años. Además, se evidencia que en la región central de Colombia (Antioquia, Caldas, Risaralda, Quindío, Caquetá, Huila, Tolima) se muestra una mayor proporción de experiencia modificada de caries $(69,98 \%)$. Por otro lado, la prevalencia modificada de caries 
es de $61,92 \%$ con un comportamiento por edades del 26,85\%, para los niños de 1 año; en los niños de 3 años se aumenta a 77,47\% y en los de 5 años a $81,86 \%$ a expensas, principalmente de la detección de los estadios incipientes de caries.

Otros estudios realizados en Colombia, demuestran la magnitud del problema de caries en dentición primaria en niños pertenecientes a contextos socioeconómicos precarios, la alta prevalencia de esta enfermedad, las necesidades de atención acumuladas en esta población, lo cual hace evidente la relación de la caries dental con la inequidad y condiciones de vida que limitan el acceso a la atención odontológica oportuna y efectiva(11,12).

Una de las causas de esta situación podría ser el desconocimiento por parte de los cuidadores, que conlleva a la práctica inadecuada de cuidado bucal en los niños a su cargo, por esto, es necesario identificar y fortalecer los hábitos presentes en esta población(13). Por otra parte, los estudios realizados sobre conocimientos, aptitudes y prácticas de padres de familia y cuidadores de niños durante su primera infancia, demuestran que ambos manifestaron condiciones favorables dentro de sus percepciones, esto puede ser una oportunidad para promocionar hábitos higiénicos en los menores, sin embargo, las prácticas que realizan los padres en la salud bucal de sus hijos no concuerdan con sus saberes y afectan su condición(14). Siendo los cuidadores y padres de familia los responsables de la primera infancia, se hace necesario determinar los conocimientos y prácticas aplicados en la salud bucal de los niños(15).

Para contrarrestar la aparición de la caries se ha propuesto metas desde las políticas gubernamentales tanto a nivel nacional como regional; una meta del Plan Decenal de Salud Pública 2012 - 2021(16) es incrementar en el 20\% la población del país sin caries, con énfasis en la primera infancia, niñez y adolescencia, reduciendo el Índice COP a 0. Por su parte, el Plan de Desarrollo de 2016-2019 Risaralda: Verde y emprendedora(17) resalta la importancia de implementar la ruta de atención integral para salud bucal mejorando la accesibilidad a los servicios de salud. También cabe mencionar la estrategia Atención Integral de las Enfermedades Prevalentes en la primera Infancia (AIEPI), la cual fue propuesta por United Nations International Children's Emergency Fund (UNICEF) y la Organización Mundial de la Salud (OMS) con el fin de reducir la incidencia y gravedad de las enfermedades que afectan a los niños; dentro de la estrategia se propone un componente bucal que sugiere tener los conocimientos básicos para promover hábitos bucales saludables en la primera infancia y destaca a las agentes educativas como sujetos protagonistas en la ejecución del AIEPI(18).

Contribuyendo con los objetivos anteriormente descritos, la Fundación Universitaria Autónoma de las Américas localizada en la ciudad de Pereira (Risaralda), ha venido trabajando desde 2010 con algunos hogares comunitarios del ICBF del departamento, algunos de ellos ubicados en el municipio de Santa Rosa de Cabal, localizado a 10 kilómetros al nororiente de la capital risaraldense. Teniendo en cuenta los factores mencionados que vulneran a la primera infancia, las políticas gubernamentales en pro del bienestar de dicha población y, considerando que no se han descrito los conocimientos y prácticas de los cuidadores que influyen en la salud bucal de los niños del municipio de Santa Rosa de Cabal, surge la necesidad de determinar los conocimientos y prácticas de las agentes educativas y condiciones de salud bucal de niños pertenecientes a los hogares comunitarios y CDI del ICBF del municipio.

\section{Materiales y métodos}

Se diseñó un estudio cuantitativo, tipo descriptivo de asociación de corte transversal, durante el año 2016; como población se consideró niños y agentes educativas de los hogares comunitarios y CDI que hacen parte del ICBF en el municipio de Santa Rosa de Cabal - Risaralda. Se incluyó 198 niños entre 1 y 5 años de edad, de estratos 1 , 2 y 3 ; 20 agentes educativas de 10 hogares comunitarios y $2 \mathrm{CDI}$; de esta manera toda la población fue incluida en la investigación. 
El equipo investigador estuvo conformado por tres profesores investigadores de la Fundación Universitaria Autónoma de las Américas y cuatro estudiantes de la Facultad de Odontología de la misma institución. Las encuestas de recolección de información fueron diseñados por los autores con base en las especificaciones dadas por la OMS en su publicación sobre métodos básicos para encuestas en salud(19) y validados por tres expertos en ciencias odontológicas que conforman el Comité Central de Investigación de la Fundación. Las evaluaciones de estos expertos presentaron un $100 \%$ de coincidencia desfavorable en 6 de los 40 ítems iniciales, por lo cual esos 6 ítems fueron excluidos de los instrumentos; en los 34 ítems restantes hubo un $100 \%$ de coincidencia favorable entre los expertos, por esta razón no hubo necesidad de reformular los instrumentos.

Para la recolección de información se realizaron tres encuestas por separado, una sobre datos sociodemográficos y otra para conocimientos y prácticas aplicadas a las agentes educativas, y la tercera encuesta para recolectar datos sociodemográficos de los niños. En la primera se midieron variables como edad, sexo, estrato, nivel de estudio de las agentes educativas. En la segunda, variables de conocimientos y prácticas de las agentes sobre salud bucal y cuidado de esta en la primera infancia y en la tercera se midieron variables como edad, sexo, estrato, hogar comunitario al que pertenecía, entre otros de la primera infancia. Además, se realizaron dos índices odontológicos para identificar las condiciones de salud bucal de la primera infancia.

Con base en los parámetros establecidos para el diseño de encuestas sobre Conocimientos, Actitudes y Prácticas, se elaboró el instrumento para indagar únicamente los conocimientos y prácticas de las agentes educativas, en relación al cuidado bucal aplicadas en la primera infancia(20).

También se realizó una encuesta para recolectar los datos sociodemográficos de los niños, y para identificar su estado de salud bucal, se aplicó dos índices odontológicos básicos con previa unificación de criterios por parte de los investigadores. Se realizó una prueba piloto como estrategia de validación del instrumento con un grupo poblacional de 14 niños pertenecientes a un hogar comunitario de la ciudad de Pereira, cada uno de los examinadores aplicó los instrumentos a cada uno de los niños de la prueba piloto, para posteriormente ser comparados. No se encontró discrepancias considerables, es decir, hubo coherencia y fiabilidad en los criterios del grupo examinador. El coeficiente Alfa-deCronbach para el instrumento fue de 0,82 dando un valor de fiabilidad bueno.

Los exámenes clínicos para determinar los índices odontológicos básicos, se realizaron en habitaciones de los hogares comunitarios y CDI, cumpliendo con las normas de bioseguridad y esterilización; cada niño se posicionó en decúbito dorsal sobre una mesa mientras el examinador estaba sentado detrás de la cabeza del infante, la iluminación utilizada fue la luz natural. Para el examen clínico se utilizó explorador, espejo bucal, tinción reveladora de placa bacteriana y gasa, es importante mencionar que antes de iniciar el examen bucal se secaban las superficies dentales con gasa; todo el instrumental se ubicó en una mesa auxiliar, y un estudiante se encargó de registrar los datos.

El primer índice odontológico básico fue el índice ceo-d modificado (cariados, extraídos, obturados) para determinar la prevalencia de caries y la historia de caries en esta población. Para el diagnóstico se tuvo en cuenta la clasificación de Pitts y Fyffe(21) que plantea la severidad de la lesión de caries, la cual puede variar entre lesión no cavitada en esmalte, lesión de esmalte cavitada, lesión en dentina cavitada, lesión con o posible compromiso pulpar; aclarando que no se hizo diferenciación en el tipo de lesión cariosa, excepto en los casos de lesión cavitaria con compromiso pulpar, en los cuales se realizó un reporte individual con el fin de informar sobre la necesidad de tratamiento prioritario. El índice ceo-d se registró en una ficha elaborada para tal fin y se clasificó los diferentes índices según los criterios definidos por la OMS(22).

También se aplicó el Índice de O’leary para determinar la higiene bucal de los participantes, aplicando una sustancia de tinción reveladora de 
placa en gotas. En el procedimiento, se suministró dos gotas reveladoras en una gasa sostenida por una pinza algodonera, se pasó por todas las superficies dentales. Posteriormente, se identificó las superficies teñidas por la sustancia que corresponden a zonas de acúmulo de depósitos bacterianos; se realizó el registro de las superficies teñidas en los formatos correspondientes y se calculó el índice de placa de O'Leary. Finalmente, para determinar el riesgo se tuvo en cuenta los parámetros establecidos en la Guía para la protección específica de la caries y la enfermedad gingival(23) que señala que un índice de placa de O'Leary por encima del $15 \%$ representa mayor riesgo de desarrollar enfermedades bucales asociadas a la placa bacteriana.

Para el procesamiento de la información de las tres encuestas y de los índices odontológicos aplicados (ceo-d y O'Leary) se digitalizaron los datos mediante tabulación en una base de Microsoft Excel ${ }^{\circledR}$. En cuanto a las características sociodemográficas de las agentes y los niños, se realizó un análisis estadístico univariado y luego bivariado. Para las encuestas de conocimientos y prácticas y los índices odontológicos, se calculó medidas de tendencia central (media, mediana y moda) y las medidas de dispersión (mínimo, máximo, desviación estándar). Se utilizó la prueba de $\mathrm{Chi}^{2}$ para evaluar la asociación entre las características sociodemográficas de los niños y su estado de salud bucal; asimismo, entre las variables de las encuestas a las agentes educativas y el estado de salud bucal de los niños. Se estableció un criterio de significancia estadística $\mathrm{p}<0,05$.

\section{Consideraciones éticas}

Esta investigación (código de proyecto P74) contó con la aprobación del Comité de Ética en Investigación de la Fundación Universitaria Autónoma de las Américas. Se aplicaron formatos para el consentimiento informado de las agentes educativas y el asentimiento informado a los acudientes de los niños; los formatos fueron firmados libremente por ambas partes, tal y como lo estipula la Resolución 8430 de 1993 del Ministerio de la Protección Social colombiano; esta investigación se clasifica como de riesgo mínimo.

\section{Resultados}

\section{Datos sociodemográficos de agentes educativas y de niños}

La población participante estuvo conformada por 20 agentes educativas de los hogares comunitarios y CDI del municipio de Santa Rosa de Cabal, pertenecientes al estrato socioeconómico 1 y 2 , su edad promedio fue de 43,1 años cumplidos (Desviación Estándar 9,4), la edad mínima fue de 33 y la máxima de 52 . Diez de ellas tenían estudios técnicos en educación de la primera infancia. Su experiencia como agentes educativas con el ICBF fue de 14,1 años en promedio.

En el estudio participaron 198 niños, de ellos, el 54\% (107) niños y el 46\% (91) niñas. El 94\% (186) pertenecían al estrato socioeconómico $1 \mathrm{y}$ 2, y $6 \%$ (12) al estrato 3. En cuanto a su área de residencia el 88,4\% (175) pertenecían al área urbana del municipio. El rango de edad estuvo entre los 1 y 5 años, con un promedio de 3,07 años cumplidos (Desviación Estándar 0,84). Los municipios de nacimiento de los niños fueron Santa Rosa de Cabal 84\% (166) y Pereira con un y un $16 \%$ (32).

\section{Conocimientos y prácticas en salud bucal de las agentes educativas}

\section{Conocimientos}

El 65\% (13) de las agentes educativas resaltaron la importancia de los dientes deciduos en el mantenimiento del espacio para la dentición permanente y el 35\% (7) como componente esencial en funciones del sistema estomatognático.

En cuanto a las enfermedades bucodentales que reconocieron como más frecuentes en la primera infancia, el 90\% (18) se refirió a la caries, por otra parte, enfermedades como la gingivitis, alteraciones del crecimiento y traumas dentales son identificadas sólo por una minoría. Para el 95\% (19) de las agentes cuidadoras, la causa 
principal asociada a estas enfermedades es el descuido por parte de los padres de familia, mientras el 5\% (1) restante lo asoció al consumo de azúcar y a la falta de higiene bucal.

El 50\% (10) de las agentes coincidieron en que el infante debe visitar al odontólogo a partir del primer año y el otro $50 \%$ (10) restante mencionaron que, a partir del nacimiento, la erupción del primer diente y a los 5 años. En cuanto a la frecuencia de la consulta odontológica, el 60\% (12) mencionaron que debe ser dos veces al año y las razones para consultar según el $90 \%$ (18) de las agentes debería ser por prevención. Los principales protagonistas en el cepillado del niño, según el 90\% (18) de las agentes, son los padres. El 95\% (19) de las agentes estuvieron en desacuerdo con el uso del biberón.

\section{Prácticas}

El 55\% (11) de las agentes expresaron que revisan la boca de los niños a su cuidado. La frecuencia del cepillado dental es diaria en el $100 \%$ de los hogares comunitarios, sin embargo, el $50 \%$ (10) de las participantes realizaban siempre el cepillado de los menores, mientras que el otro 50\% (10) lo hacían sólo algunas veces.
Los implementos utilizados por el $100 \%$ de las agentes para llevar a cabo la higiene bucal en los hogares fueron el cepillo y la crema dental, mientras que la seda dental no se utilizó en ninguno de los hogares. Para dispensar la crema el 55\% (11) de las agentes lo hacían sobre el eje vertical del cepillo, aplicando una cantidad elevada. Respecto al flúor en la crema dental que se usa para cepillar los niños, el 60\% (12) de las agentes dijo que ésta no debe contener flúor, el $25 \%$ (5) dijo que el flúor debe estar presente, mientras que el 15\% (3) manifestó no saber.

\section{Condiciones de salud bucal de los niños}

El promedio de dientes presentes en boca de los niños fue de 19,5, el índice ceo-d modificado fue de 3,1 (Desviación Estándar 3,3); describiendo cada componente del índice se encontraron los siguientes promedios generales: cariados $(2,6)$ extraídos $(0,1)$ y obturados $(0,4)$. El promedio del índice de O'Leary fue del 61,3\% que se traduce en riesgo alto de caries y enfermedades asociadas a placa bacteriana al ser mayor a 15\%. Los hallazgos de las condiciones bucales de los niños se muestran con sus datos sociodemográficos. (Tabla 1).

Tabla 1. Hallazgos condiciones bucales de las niñas y niños según condiciones sociodemográficas. Santa Rosa de Cabal

\begin{tabular}{lrrrrr}
\hline \multicolumn{1}{c}{ Sexo } & $\begin{array}{c}\text { Promedio de } \\
\text { ceo- d }\end{array}$ & $\begin{array}{c}\text { Promedio de } \\
\text { cariados }\end{array}$ & $\begin{array}{c}\text { Promedio de } \\
\text { obturados }\end{array}$ & $\begin{array}{c}\text { Promedio de } \\
\text { extraídos }\end{array}$ & $\begin{array}{c}\text { Promedio de índice de } \\
\text { O'leary (\%) }\end{array}$ \\
\hline Hombre & 3,4 & 2,9 & 0,4 & 0,1 & 63,8 \\
Mujer & 2,7 & 2,3 & 0,4 & 0,1 & 58,4 \\
Edad (años cumplidos) & & & & & 75,0 \\
1 & 0,0 & 0,0 & 0,0 & 0,0 & 59,4 \\
2 & 2,6 & 2,5 & 0,1 & 0,0 & 59,3 \\
3 & 3,0 & 2,4 & 0,5 & 0,1 & 63,5 \\
4 & 3,7 & 3,0 & 0,5 & 0,2 & 84,2 \\
5 & 2,3 & 2,3 & 0,0 & 0,0 & 67,1 \\
Estrato socioeconómico & & & & 55,1 \\
1 & 3,8 & 3,1 & 0,5 & 0,2 & 62,2 \\
2 & 2,7 & 2,4 & 0,3 & 0,0 & \\
3 & 0,4 & 0,3 & 0,2 & 0,0 & 60,8 \\
Área de residencia & & & & & 52,6 \\
Rural & 3,5 & 3,3 & 0,2 & 0,0 & 61,3 \\
Urbana & 3,0 & 2,8 & 0,2 & 0,1 & \\
Total niños & 3,1 & 2,6 & 0,4 & 0,1 & \\
\hline
\end{tabular}

La experiencia modificada de caries hace referencia a la proporción de personas que al momento de la aplicación del índice ceo-d presentan evidencia de haber sufrido en algún 
momento de su vida caries en alguna de sus fases y secuelas, como obturados o perdidos por caries, en este caso para la población de primera infancia fue del 22,7\%; la prevalencia modificada de caries se refiere al porcentaje de niños con lesiones de caries al momento de la aplicación del índice ceo$\mathrm{d}$ que incluye caries cavitacional, lesiones iniciales y/o lesiones moderadas. La prevalencia modificada de caries de la primera infancia fue del $63,6 \%$. (Tabla 2)

Tabla 2. Prevalencia y experiencia modificada de caries de niños

\begin{tabular}{crr}
\hline Edad & $\begin{array}{c}\text { Prevalencia } \\
\text { modificada de } \\
\text { caries \% }\end{array}$ & $\begin{array}{c}\text { Experiencia } \\
\text { modificada de } \\
\text { caries \% }\end{array}$ \\
\hline $\mathbf{1}$ & 0 & 0 \\
$\mathbf{2}$ & 18,6 & 4,04 \\
$\mathbf{3}$ & 22,2 & 10,1 \\
$\mathbf{4}$ & 22,2 & 8,5 \\
$\mathbf{5}$ & 0,5 & 0 \\
Niños & 63,6 & 22,7 \\
\hline
\end{tabular}

Asociación de condiciones de salud bucal de niños con datos sociodemográficos y con los conocimientos y prácticas de las agentes educativas

Se determina una asociación estadísticamente significativa entre el índice ceo-d, el área de residencia y el estrato socioeconómico (Tabla 3). Con las demás variables sociodemográficas no se evidencia asociación estadística. El índice de O’Leary no muestra asociación con ninguna de las variables sociodemográficas. No se encontró relación significativa entre conocimientos y prácticas de agentes con el estado de salud bucal.

Tabla 3. Resultado de la asociación entre variables sociodemográficas y el índice ceo-d de los niños

\begin{tabular}{lrr}
\hline \multicolumn{1}{c}{$\begin{array}{c}\text { Variables } \\
\text { sociodemográficas } \\
\text { primera infancia }\end{array}$} & Chi' $^{2}$ & Valor p \\
\hline Sexo & 4,26 & 0,3716 \\
Edad & 13,12 & 0,664 \\
Estrato socioeconómico & 24,69 & $0,0018^{*}$ \\
Área de residencia & 17,68 & $0,0014^{*}$ \\
\hline *Diferencia de proporciones estadísticamente significativa (valor \\
p $<0,05)$
\end{tabular}

\section{Discusión}

En cuanto a los conocimientos sobre salud bucal de las agentes educativas del presente estudio, se demuestra que comprenden la importancia de la dentición temporal, sin embargo, desconocen la mayoría de enfermedades bucales, reconociendo la caries como la principal, la cual es causada, según ellas, por el descuido de los padres de los menores. Estos hallazgos concuerdan con los resultados de otros estudios realizados con agentes y madres en Medellín(9), donde además se resalta la necesidad de capacitar a los cuidadores sobre las enfermedades bucales más frecuentes de la primera infancia y su prevención. Para González(24), las técnicas de higiene bucal en los infantes implican cierto grado de dificultad por su corta edad, falta de cooperación y el tiempo que demanda la labor, evidenciando la vulnerabilidad de esta población por su dependencia de los adultos.

El 50\% de las agentes refirieron que la primera visita del infante al odontólogo debe ser al primer año de vida; sin embargo, se debe tener en cuenta que los rodetes gingivales y los dientes presentes pueden desarrollar múltiples enfermedades si no se lleva a los niños a consulta odontológica antes de este periodo. Respecto a esto, autores como Valencia, et al.(25), afirman que es poco frecuente que un odontólogo trate niños menores de 3 años, Juárez, et al.(26), resaltan que la mayoría de las veces la consulta al odontólogo es tardía y ocurre cuando el paciente presenta dolor, lo cual implica tratamientos complejos a una edad muy temprana. Por su parte, González et al.(9), exponen en su investigación que las agentes educativas manifestaron encontrar barreras de acceso en los servicios de salud, argumentando que en las Instituciones Prestadoras de Servicios de Salud, les indican que los menores están muy pequeños para ser atendidos por el odontólogo de la institución. Lo anterior, sugiere la necesidad de que los odontólogos deben ser formados para la atención integral de la primera infancia dando accesibilidad a esta población de escasos recursos que no tienen oportunidad de ser atendidos en el sector privado. 
En lo concerniente al uso de cremas dentales con flúor en la primera infancia, cabe mencionar la problemática de fluorosis dental que está aumentando en Colombia y en otras partes del mundo, debido a que se ha evidenciado una ingestión de flúor de forma sistémica en los niños pequeños que la usan, por tanto, es recomendando fabricar dentífricos con pocas cantidades de fluoruro o sin esta partícula para esta población(27). Al respecto el Ministerio de Salud y Protección Social de Colombia recomienda emplear una cantidad muy pequeña de pasta dental que debe ser suministrada por los adultos(28). No obstante, las agentes educativas encuestadas no llegaron a un consenso respecto al tema, pues, aunque el $60 \%$ indica que no se debe utilizar crema dental con flúor en los menores, el $40 \%$ no tiene claridad acerca de esta práctica y adicionalmente el 55\% de ellas aplican una cantidad elevada de dentífrico para cepillar a los niños a su cargo. Del mismo modo se evidenció en Cartagena(14) un porcentaje mayor $(66,4 \%)$ de cuidadores de primera infancia que aplican una cantidad de crema de más de la mitad del largo del cepillo.

Con respecto a las prácticas de higiene bucal de las agentes educativas, se evidencia que ninguna utilizaba la seda dental en los infantes de los hogares comunitarios, una situación similar relató Agudelo(27) en su investigación, explicando que este fenómeno se debe a la edad de los infantes, el costo del producto y la poca apropiación de este hábito por parte de la población adulta. Por consiguiente, se hace necesario promocionar el uso de los implementos de higiene bucal y su adecuado manejo en la primera infancia.

En relación a las condiciones de salud bucal de los niños participantes de la presente investigación, el índice ceo-d presentó un promedio de 3,1, el cual bajo los criterios de la Organización Mundial de la Salud (OMS)(22) es moderado; resultados similares se encontraron en un estudio realizado en Medellín sobre caries dental en niños de 3 a 5 años, donde se reporta un promedio de 3,4(29). Teniendo en cuenta la meta de reducir a 0 el índice de caries planteada en el Plan Decenal de Salud Pública 2012-2020(16), se evidencia la necesidad de implementar estrategias que impacten con mayor efectividad en la salud bucodental de esta población. También se reportaron en investigaciones de otros países promedios del índice ceo-d similares en primera infancia, en Perú( ${ }^{(30)}$ de 2,9, en Ecuador(31) de 2,5, en Argentina(32) 2,1 y en México(33) 3,5, estos son promedios catalogados como moderados, lo que puede indicar que no es una problemática exclusivamente nacional.

El índice ceo-d también evidencia que la experiencia modificada de caries es del $22,7 \%$ es decir, que durante la primera infancia ya ha presentado caries en estadios avanzados, evidenciado en dientes obturados y/o perdidos por la misma causa. La cifra anterior se encuentra por debajo de la que se reporta en el ENSAB IV(10) que fue de $66,91 \%$. Sin embargo, en cuanto a la prevalencia modificada de caries, el resultado obtenido en esta investigación $(63,6 \%)$ fue mayor a la cifra nacional de $61,92 \%$ reportada en el ENSAB IV(10). Al igual que en otras ciudades de Colombia como en Villavicencio(34) y Zipaquirá(35) con prevalencia de $93 \%$ y $92 \%$ respectivamente. En el panorama internacional se encuentran estadísticas cercanas a las encontradas en la presente investigación; en Argentina(25) de 63\% y en Ecuador( ${ }^{(31)}$ de $68 \%$.

El promedio del índice de 0’Leary fue del 61,3\%, que según la Guía para la protección específica de la caries y la enfermedad gingival(27) indica el riesgo en los niños de desarrollar enfermedades bucodentales. Aunque este promedio es alto, otras investigaciones revelan índices mayores para la primera infancia, en Colombia( ${ }^{(35)}$ de $98,7 \%$ y en Chile(36) de 70,1\%.

El avance de las enfermedades bucales que se muestra en los niños, evidencia la necesidad de coordinar esfuerzos intersectoriales por parte de la academia, los odontólogos, las instituciones de salud y el ICBF, brindando herramientas y recursos que permitan generar mayor adherencia a los servicios odontológicos, incluyendo la promoción de la salud bucal y la prevención de las enfermedades por parte de la población responsable de la primera infancia que asiste a los hogares comunitarios y CDI del Municipio de 
Santa Rosa de Cabal, por cuanto se debe tener en cuenta que las enfermedades bucales repercuten negativamente en la calidad de vida de los individuos generando alteraciones en el crecimiento corporal, la masticación, el apetito, el sueño, el comportamiento y en el rendimiento escolar, que afecta el bienestar general de esta población(37).

En los resultados se determina una asociación estadísticamente significativa entre el índice ceo$\mathrm{d} y$ el área de residencia $(\mathrm{p}=0,0014)$. Al respecto, en Andes, Antioquia(38), se muestra una prevalencia mayor de caries en la zona rural que en la urbana. También se encuentra en la presente investigación asociación estadística entre el índice ceo-d y el estrato socioeconómico $(p=0,0018)$ similar a lo establecido en otras investigaciones en Cartagena( ${ }^{(39)}$ y en Lima ${ }^{(30)}$ con asociaciones de $p=0,04$ y $p=0,0001$ respectivamente. Lo anterior señala que el estrato socioeconómico bajo y pertenecer a la zona rural son barreras para acceder a los servicios odontológicos del sistema de salud, reflejando inequidades para la primera infancia que aún no se han logrado solventar.

Con las demás variables sociodemográficas no se establece asociación estadística con el índice ceod. El índice de O'Leary tampoco arroja asociación con ninguna de estas, sin embargo, la literatura reporta asociaciones significativas entre los grupos de edad y la presencia de caries(38) y entre el índice de 0'Leary y la prevalencia de caries(30).

No se encuentra en el presente estudio, asociación estadística entre los conocimientos y prácticas de las agentes con las condiciones de la salud bucal de los niños, resultado equivalente a una investigación realizada en Chile(36) con madres de familia, donde se reporta que no existe asociación entre sus conocimientos con el estado de salud bucal de sus hijos. Sin embargo, la primera infancia no deja de ser una población vulnerable debido a la dependencia de sus cuidadores, por lo cual se debe continuar ahondando en la prevención de enfermedades, el seguimiento y tratamiento a estas, así como en la promoción de la salud bucal, interviniendo conjuntamente con todos los actores involucrados en el crecimiento y desarrollo de estos.

Para lograr intervenciones exitosas en esta población y mejorar las condiciones de su situación de salud bucal es fundamental iniciar con educación para la salud, involucrando a los actores directamente responsables de la primera infancia. Sin embargo, priorizar en resolver las inequidades en seguridad alimentaria, ingreso económico, dinámica familiar y condiciones de trabajo ${ }^{(40)}$ implica un compromiso intersectorial que permite incidir positivamente en los determinantes sociales, los cuales influyen directamente en el proceso salud-enfermedad bucal.

\section{Conclusiones}

En cuanto a los conocimientos las agentes educativas desconocían la mayoría de las patologías bucales de la primera infancia y el momento oportuno de iniciar la consulta odontológica de un infante, en las prácticas aplicaban gran cantidad de dentífrico para el cepillado de los niños y niñas, sin tener en cuenta el contenido de flúor y no utilizaban la seda dental. En las condiciones de salud bucal, los niños y niñas presentaron índice ceo-d con un promedio de 3,1 , la experiencia modificada de caries fue del $22,7 \%$, la prevalencia modificada de caries fue de $63,6 \%$ y el promedio del índice de O'Leary fue del $61,3 \%$.

Los programas de hogares comunitarios y los CDI del ICBF, son una estrategia donde se vela por el bienestar de los niños; sin embargo, la alta prevalencia de caries y de placa bacteriana que presenta esta población, evidencia la necesidad de fortalecer los programas de intervención en salud bucal donde se evalúen los factores de riesgo y se priorice en la adquisición temprana de hábitos bucales saludables capacitando a agentes educativas y padres de familia.

Estos programas deben tener continuidad desde la iniciativa del ICBF en conjunto con las instituciones de salud, mejorando el acceso y oportunidad de atención odontológica a partir de edades tempranas, y con las facultades de 
odontología, donde se forman profesionales competentes para la atención integral de la primera infancia.

Todos los esfuerzos en pro del bienestar de los niños, incluyendo las investigaciones e intervenciones con esta población, se deben replicar en los distintos municipios del territorio nacional para prevenir las enfermedades, disminuir los índices de morbilidad bucal actuales y a partir del contexto y la situación de salud bucal generar estrategias participativas que involucren a todos los actores responsables del cuidado de la primera infancia.

Se recomienda para futuras investigaciones en salud bucal de la primera infancia, tener en cuenta la posibilidad de realizar asociaciones, entre sus condiciones de salud y otros determinantes sociales que permitan comprender a mayor profundidad las dinámicas entre estos y las enfermedades bucales.

\section{Conflicto de intereses}

Ninguno declarado por los autores.

\section{Referencias}

1. Organización Mundial de la Salud [Internet]. El desarrollo del niño en la primera infancia y la discapacidad. Ginebra: OMS; 2013 [citado 2018 Jul 25]. Disponible en: https://www.unicef.org/earlychildhood/files/ECDD_S PANISH-FINAL_(low_res).pdf

2. Aubert J, Sanchez S, Castro R, Monsalves MJ, Castillo P, Moya P. Calidad de vida relacionada con salud oral en mayores de 14 Años en la Comunidad San Juan Bautista, Isla Robinson Crusoe, Chile. Int J odonstomatology. 2014;8(1):141-5

3. Fondo de las Naciones Unidas para la Infancia [Internet]. Estado mundial de la infancia 2016 una oportunidad para cada niño. Nueva York: UNICEF; 2016 [citado 2017 Mayo 20]. Disponible en: https://www.unicef.org/spanish/publications/files/U NICEF_SOWC_2016_Spanish.pdf

4. Ministerio de Educación Nacional de Colombia [Internet]. Documento de orientaciones técnicas, administrativas y pedagógicas para la atención educativa a estudiantes con capacidades y/o talentos excepcionales en el marco de la educación inclusiva. Bogotá: MinEducación; 2015 [citado 2017 Mayo 10]. Disponible en: http://fundacionfes.org/sitio/wp-
content/uploads/2016/02/Documento_Orientaciones _Educacion_Inclusiva.pdf

5. Departamento Administrativo Nacional de Estadística [Internet]. Pobreza Monetaria Y Multidimensional en Colombia. Bogotá: DANE; 2015 [citado 2016 Noviembre 13]. Disponible en: https://www.dane.gov.co/files/investigaciones/condi ciones_vida/pobreza/bol_pobreza_15_.pdf

6. Instituto Colombiano de Bienestar Familiar [Internet]. Caracterización del maltrato infantil en Colombia: Una aproximación en cifras. Bogotá: ICBF; 2013 [citado 2017 Mayo 13]. Disponible en: https://www.icbf.gov.co/sites/default/files/publicaci on-37.pdf

7. Osorio Y, Cortés L, Rodas M. De madres Comunitarias a Agentes Educativos: Experiencia y Formación. Vicisitudes de un Trayecto [tesis], Medellín: Universidad de Antioquia; 2016

8. Blanco MJ, Arias CA. Rasgos individuales y académicos de madres comunitarias en cualificación. Horizontes Pedagógicos. 2016;18(2):39-51.

9. González C, Cano MC, Meneses EJ, Vivares AM. Perceptions of children's oral health. Rev Latinoam Ciencias Soc Niñez y Juv. 2015;13(2):715-24.

10. Ministerio de Salud y Protección Social [Internet]. Estudio Nacional De Salud Bucal - ENSAB IV. Bogotá, Colombia: MinSalud; 2014 [citado 2017 Marzo 20]. Disponible https://www.minsalud.gov.co/sites/rid/Lists/Bibliot ecaDigital/RIDE/VS/PP/ENSAB-IV-Situacion-BucalActual.pdf

11. Ramírez BS, Escobar G, Franco Am, Ochoa EM, Otálvaro GJ, Agudelo AA. Caries dental en niños de 0-5 años del municipio de Andes, Colombia. Evaluación mediante el sistema internacional de detección y valoración de caries - ICDAS. Rev. Fac. Nac. Salud Pública. 2017;35(1):91-98.

12. Hurtado CF, Potes DA, Vásquez M, Posada A, Álvarez LG, Agudelo AA. Higiene bucal, caries dental y necesidades de tratamiento en escolares de 5, 7 y 12 años, municipio de Istmina, Chocó, Colombia. Univ Odontol. 2017;36(77):1-14.

13. Ruiz AJ, Galvis JA, Gómez VA, Salinas AM, Agudelo A. Proyecto pedagógico para el aprendizaje de prácticas bucales saludables con niños y niñas escolarizados entre 8 y 10 años. Infancias Imágenes. 2015;14(1):4049.

14. Gonzáles F, Sierra CC, Morales LE. Conocimientos, actitudes y prácticas en salud bucal de padres y cuidadores en hogares infantiles, Colombia. Salud Pública Mex. 2011;53(3):247-257.

15. González C, Cano M, Meneses EJ, Saldarriaga V. Conocimientos en salud bucal de los cuidadores del Programa Buen Comienzo. Rev Gerenc y Polit Salud. 2016;15(31):130-44

16. Ministerio de Salud y Protección Social Colombia [Internet]. Plan Decenal de Salud Pública. 2012 - 2021. Bogotá: MinSalud; 2013 [citado 2017 Abril 15]. Disponible http://www.minsalud.gov.co/Documentos 
Publicaciones/Plan Decenal - Documento en consulta para aprobación.pdf

17. Gobernación de Risaralda [Internet]. Plan De Desarrollo 2016-2019 Risaralda: Verde Y Emprendedora. Risaralda: Gobernación de Risaralda; 2016. [citado 2017 Abril 15]. Disponible en: www.risaralda.gov.co/descargar.php?idFile $=22835$

18. Ministerio de Protección Social y Organización Panamericana de la Salud OPS/OMS [Internet]. Componente comunitario de la estrategia AIEPI: Guía para madres comunitarias. Bogotá: MinSalud; 2010 [citado 2017 Julio 05]. Disponible en: https://www.minsalud.gov.co/sites/rid/Lists/Bibliot ecaDigital/RIDE/VS/PP/Guia_madres_comunitarias.p df

19. World Health Organization. Oral Health Surveys - Basic Methofd [Internet]. Geneva: WHO; 2013 [citado 2016 Agosto 05]. Disponible en: http://apps.who.int/iris/bitstream/handle/10665/41 905/9241544937.pdf?sequence=1\&isAllowed=y

20. Holman A. Encuestas de conocimientos, actitudes y prácticas en el ámbito de la protección de la infancia [Internet]. Londres: Save the Children; 2012. [citado 2017 Octubre 02]. Disponible en: https://resourcecentre.savethechildren.net/sites/defa ult/files/documents/kap_report_sp_hi-res_0.pdf

21. Pitts NB, Fyffe HE, Piuts NB. The Effect of Varying Diagnostic Thresholds upon Clinical Caries Data for a Low Prevalence Group. J Dent Res. 1988;67(3):592596.

22. Ministerio de Salud Pública y Asistencia Social Guatemala [Internet]. Estudio epidemiológico de caries dental y fluorosis. Guatemala: Ministerio de Salud Pública y Asistencia Social; 2002 [citado 2016 Noviembre 02]. Disponible en: http://new.paho.org/hq/dmdocuments/2009/0HGUTcpo.pdf

23. Ministerio de la Protección Social. Guía para la protección específica de la caries y la enfermedad gingival [Internet]. Guías promoción la salud y prevención enfermedades en la salud pública. Bogotá: MinSalud; 2005 [citado 2014 Octubre 01]. Disponible en:

http://www.nacer.udea.edu.co/pdf/libros/guiamps/g uias07.pdf

24. González GE. Jardín Infantil de la Universidad Nacional de Colombia: evaluación de un programa para la promoción de salud bucal en la primera infancia. Univ Odontológica. 2012;31(66):57-72.

25. Valencia C, Bermúdez P, Hernández A, Restrepo O, Cortés Á. Barreras de acceso a la atención odontológica durante la primera infancia. Revista Facultad de Odontología Universidad de Antioquia. 2014; 25(2):325-341.

26. Juárez LA, Ugalde RR, Delgado AA. Factores de riesgo asociados con el estado de ansiedad en niños de cuatro a seis años de edad que acuden por primera vez con el odontopediatra. Revista ADM. 2014;71(1):9-15.

27. Agudelo A, Martínez L, Madrid LM, Vivares A, Rocha A. Panorama de la fluorosis dental en Colombia: una revisión exploratoria de la literatura. Univ Odontol. 2013;32(68):133-45.

28. Ministerio de Salud y Protección social. Documento técnico política de flúor vs caries y fluorosis dental en Colombia. Bogotá: MinSalud; 2016 [Internet]. [Consultado: 2018, 07, 27]. Disponible en: https://www.minsalud.gov.co/sites/rid/Lists/Bibliot ecaDigital/RIDE/VS/PP/ENT/perspectiva-usofluor.pdf

29. Gómez AM, Bernal T, Posada A, Agudelo AA. Caries dental, higiene bucal y necesidades de tratamiento en población de 3 a 5 años de una institución educativa de Medellín y sus factores relacionados. Rev Nac Odontol. 2015;11(21):23-35.

doi: http://dx.doi.org/10.16925/od.v11i21.933

30. Villena R. Prevalencia de caries de infancia temprana en niños menores de 6 años de edad, residentes en poblados urbano marginales de Lima Norte. Rev Estomatol Hered. 2011;21(2):79-86.

31. Valarezo TL, Mariño SM. Prevalencia de caries temprana de la infancia en cuatro guarderías del norte Quito-Ecuador. Dom Cien. 2017;3(1):278-97.

32. Gonzalez MM, Pérez SR. Epidemiología de la caries dental en niños del Jardín de Infantes "Pinocho" de la ciudad de Corrientes. Revista Facultad de Odontología. 2016;9(1):35-41.

33. Molina N, Duran D, Castañeda E. La caries y su relación con la higiene oral en preescolares mexicanos. Gac Med Mex. 2015;151(4):485-90.

34. Chavarría N, Durán L, Díaz M, Pinzón J, Torres D. Prevalencia de caries de la primera infancia y exploración de factores de riesgo. Rev Colomb Investig en Odontol. 2013;4(10):56-64.

35. Macías C, Díaz D, Caycedo M, Lamus F, Rincón C. Asociación de caries de infancia temprana con factores de riesgo en hogares comunitarios del Instituto Colombiano de Bienestar Familiar en Zipaquirá, Colombia. Rev Fac Odontol. 2016;28(1):123-38

36. Farías J. Estado de salud oral de niños de 4-5 años y nivel de conocimientos materno, Concepción 2015 [tesis], Concepción: Universidad Andrés Bello; 2015.

37. Tello G, Abanto J, Oliveira LB, Sato CM. Impacto de los principales problemas de salud bucal en la calidad de vida de preescolares. Revista odontología. 2016;19:4252.

38. Escobar G, Ochoa EM. Caries dental en niños de 0-5 años del municipio de Andes, Colombia. Evaluación mediante el sistema. Rev Fac Nac Salud Pública. 2016; 35(1):92-8.

39. Díaz S, Arrieta K, Ramos K. Funcionalidad familiar y estado nutricional. Rev Colomb Investig en Odontol. 2015;6:16

40. Martínez J, Castell P, Llanes E, Morales O. Componente bucal y determinantes sociales en el análisis de la situación de salud. Revista Cubana de Estomatología. 2015;52:53-61. 